\title{
1973 de José Ángel Cuevas: una poética del disenso y la parodia frente a la narrativa de la (des)memoria oficial*
}

\author{
1973 by José Ángel Cuevas: a poetics of dissent and parody against \\ the narrative of official (un)memory \\ María José Barros Cruz \\ Pontificia Universidad Católica de Chile. Correo electrónico:mjbarro1@uc.cl
}

En el artículo propongo que la narrativa de la memoria elaborada en 1973 de José Ángel Cuevas se construye desde la óptica de los vencidos y mediante la parodia de los documentos judiciales. Desde esta perspectiva, analizo el texto como una poética del disenso, que polemiza con la memoria oficial instalada por los gobiernos de la Concertación, donde los recuerdos de las subjetividades heridas han sido excluidos en favor del consenso.

Palabras clave: José Ángel Cuevas, dictadura, memoria, herida, Transición.

In this article I propose that the narrative of memory elaborated in 1973 by José Ángel Cuevas is constructed from the optic of losers and through the parody of judicial documents. From this standpoint, I analyze the text as a poetics of dissent that confronts the official memory established by the Concertación's governments, where memories of wounded subjectivities have been excluded in favor of consensus.

Key words: José Ángel Cuevas, dictatorship, memory, wound, Transition.

Tuvieron a Pinochet en sus manos y lo salvaron. Ahora Tom Matamala odia a la Concertación

sus amigos europeos

Son unos conchesumadre, me dice.

Con respecto a ese pasado tenemos que repensar

lo que se consumó.

“Algo sobre la Concertación” de Maquinaria Chile y otras escenas de poesía política

José Ángel Cuevas

Becaria de Doctorado Nacional Conicyt. Este artículo fue elaborado en el marco del proyecto Fondecyt n 1120264

"Las comidas y las bebidas en la poesía chilena". 


\section{A MODO DE INTRODUCCIÓN}

El 11 de septiembre del 2003 se cumplieron treinta años del golpe de Estado. A propósito de esta fecha conmemorativa, José Ángel Cuevas publicó el poemario 1973, que como otras obras del poeta no llamó mayormente la atención de la crítica. Al inicio del libro, el escritor explica brevemente su intención: "Esta documentación pública del realismo sucio chileno carga voces distintas y objetuales que el autor ha querido recoger cuando se cumplen treinta años de la tragedia 1973 (de la cual todavía no salimos)" (Cuevas 2003: s/n). Si las Fuerzas Armadas justificaron el llamado pronunciamiento militar en aras de la salvación de la patria, para Cuevas el golpe militar es sinónimo de una "tragedia" de la que aún no nos recuperamos. Esta óptica de los vencidos permea toda su obra y 1973 no es la excepción. En este sentido, me propongo analizar la narrativa de la memoria elaborada en este texto poético y cómo dialoga con los relatos oficiales construidos durante la Transición por los gobiernos de la Concertación. Para establecer este diálogo, me parece importante realizar primero algunos comentarios sobre lo ocurrido -tanto a nivel mediático como político- durante el año 2003, y luego proponer algunas directrices sobre el concepto de memoria.

Con algunos meses de antelación al 11 de septiembre, los distintos canales de televisión comenzaron a saturar las pantallas de los televidentes con secuencias audiovisuales del bombardeo de La Moneda y otras escenas de la dictadura. Como indicó Nelly Richard en aquel entonces, se produjo una "sobreabundancia de flashes que, excitadamente, competían por ponerse al día en materia de olvido" (Richard 2004: 12). Paralelamente, Ricardo Lagos presentó en el mes de agosto la propuesta de su gobierno en materia de derechos humanos, titulada No hay mañana sin ayer (2003). En este documento, el primer mandatario decía: "Hago entrega al país de la propuesta de mi gobierno para seguir avanzando en el delicado proceso de sanar heridas producidas por las graves violaciones a los derechos humanos ocurridas entre el 11 de septiembre de 1973 y el 10 de marzo de 1990" (Lagos 2003: 4). Además, el mismo día en que se cumplían las tres décadas del golpe militar, Lagos realizó otro gesto importante: la reapertura de la puerta de Morandé 80, usada tradicionalmente por los presidentes para ingresar a La Moneda, pero que fue clausurada y tapada con concreto por los militares luego de sacar el cadáver de Allende. Si bien el discurso oficial asumía que en la comunidad nacional aún existían heridas por sanar, la retórica del consenso y la reconciliación -tan característica de los años 90- seguía presente.

Según Tomás Moulián, "el consenso es la etapa superior del olvido" (Moulián 2002: 42). Una tendencia amnésica promovida por la clase dirigente durante la Transición, con el propósito de lograr lo que el sociólogo ha denominado el "blanqueo" de Chile, operación transformista que habría de "asegurar y orquestar las nupcias ejemplares entre la neodemocracia y el neocapitalismo" (Moulián 2002: 41). En una línea similar, Nelly Richard entiende el consenso como un dispositivo discursivo de control, que buscó neutralizar las significaciones conflictivas y polarizadas en torno al pasado dictatorial, oficializando de esta forma un "idioma del acuerdo" (Richard 2001b: 16). El resultado es la elaboración de una memoria pública sin marcas de violencia ni sufrimiento, acorde con el discurso de la alegría promovido por la campaña del No y la imagen de país exitoso que se deseaba proyectar: "El libreto oficial del gobierno de la Concertación ha convertido la memoria en una doble cita, respetuosa 
y casi indolora. Tribunales, comisiones y monumentos a los derechos humanos citan regularmente a la memoria (hacen mención de ella, la notifican), pero dejando fuera de sus hablas diligentes toda la materia herida del recuerdo" (Richard 2001a: 31).

En este contexto Cuevas publica 1973, libro que ubico dentro de lo que Michael Lazzara ha llamado las voces del disenso, definidas como "voces de la sociedad chilena que han realizado importantes críticas y han combatido las políticas del olvido desde posiciones sociales marginales, menos poderosas, más contestarías" (Lazzara 2007: 53). Desde la tribuna de la poesía y acorde con la visión crítica de la sociedad postdictatorial manifestada en sus obras anteriores, el poeta arremete nuevamente contra la narrativa de la memoria oficial o pública elaborada por la Concertación ${ }^{1}$. Ya en Proyecto de País (1994) la voz de Efraín L. Sepúlveda Fica hacía visible el discurso de la higiene de la Transición ${ }^{2}$, que ordenaba lavar, limpiar, botar y cubrir cualquier rastro del pasado dictatorial, haciendo del olvido su estandarte: "Había que lavar calles, raspar grasa, barrer mugre, sangre, gritos, vómitos pegados. Restregar murallas, cambiar asientos, telarañas, mierda de gato, pichí de gato y tapar hoyos, botar escombros" (Cuevas 2009: 65). Mi lectura es que la obra que ahora nos ocupa también se erige como una polémica explícita hacia la memoria oficial, entendida como un relato insuficiente y homogeneizante, que se ha instalado a costa de la exclusión de las subjetividades que reivindican el derecho a hacer pública su memoria herida. En este sentido, la obra de Cuevas puede ser definida como una poética del disenso y paródica, que asume una posición concreta en la pugna por el significado de nuestros recuerdos colectivos.

¿Pero qué entendemos por memoria? En sus estudios sobre las memorias del Holocausto y la influencia de los nuevos medios como vehículos de éstas, Andreas Huyssen comenta el debate surgido a propósito de la comparación entre las películas Shoah de Lanzmann y La lista de Schindler de Spielberg, circunstancia en la que algunos críticos señalaron que la primera entregaba una representación más adecuada, mientras que la segunda respondía una trivialización comercial (Huyssen 2007: 25). En contra de este argumento, el intelectual alemán propone un nuevo enfoque para abordar dicha discusión: todas las memorias son representaciones y, por lo tanto, existen múltiples posibilidades de dar cuenta de ese pasado que se desea rememorar. A su vez, éstas pueden coexistir con otros propósitos - comerciales, por ejemplo-y ostentar distintos niveles de calidad y aceptabilidad. En sus palabras:

Es que una vez que reconocemos la brecha constitutiva que media entre la realidad y su representación en el lenguaje o la imagen, debemos estar abiertos en principio hacia las diferentes posibilidades de representar lo real y sus memorias. Esto no significa que cual-

Según Barahona de Brito, la política de la memoria -concepto que retoma de Guillermo O’ Donell- involucra dos instancias de realización: la memoria oficial o pública y la memoria social. En palabras de la académica: "Estrictamente concebida, se refiere a las políticas diseñadas para lidiar con el pasado en la transición (memoria oficial o pública); de manera más amplia, se trata de cómo la sociedad interpreta y se apropia de su pasado (memoria social)" (Barahona de Brito et al. 2002: 69).

Magda Sepúlveda, en su artículo "Metáforas de la higiene y la iluminación en la ciudad poetizada bajo el Chile autoritario", analiza un conjunto de textos poéticos y videos producidos durante la dictadura, que al trabajar sobre los núcleos simbólicos de la higienización y la iluminación dialogan con el discurso de la limpieza promovido por el autoritarismo militar (Sepúlveda 2008: 68). Tomando en consideración esta lectura, se puede señalar que la poesía postdictatorial de Cuevas revela cómo la retórica del consenso promovida por los gobiernos de la Transición continúa con el imperativo higiénico de la dictadura, donde limpiar ha devenido en olvidar. 
quier opción resulte aceptable. La calidad sigue siendo una cuestión a definir caso por caso. Sin embargo, no se puede cerrar la brecha semiótica con una única representación, la única correcta (Huyseen 2007: 25).

A partir de lo anterior, comprendo que la memoria es una construcción cultural y no una verdad única e irrefutable sobre el pasado. En este sentido, el relato mnémico elaborado por Cuevas sobre la dictadura es tan válido y legítimo como el propuesto -por ejemplo- en la exitosa serie de televisión Los 80, donde a mi parecer el foco está puesto no solo en contar una historia atractiva y cercana, sino en despertar la nostalgia del espectador por la estética cotidiana de una época.

Por otra parte, rescato también dos conceptos desarrollados por Lazzara en su estudio sobre las narrativas de la memoria en el Chile postdictatorial: el prisma y el lenguaje. El primero dice relación con lo anunciado en el título de su libro, Prismas de la memoria: narración y trauma en la transición chilena, que niega la objetividad de cualquier relato, relevando el filtro desde el cual se recuerda, interpreta y reescribe el pasado: "Propongo el término prismas de la memoria como una forma de referirse al lugar subjetivo desde el que la víctima (o el artista) habla. El prisma, como metáfora, evoca refracciones (ideológicas, genéricas, o de cualquier otra) a las que están sometidas las memorias cuando son contadas" (Lazzara 2007: 61). El segundo dice relación con qué lenguajes, formas narrativas o poéticas se articulan en las distintas obras analizadas en su libro, con el fin de hacer memoria de un episodio traumático de la historia nacional reciente: "Ciertamente, hoy, a más de tres décadas del golpe, el tema ya no es si efectivamente se cometieron atrocidades durante la dictadura, sino cómo dichas atrocidades están siendo interpretadas, comprendidas y traducidas en palabra e imagen" (Lazzara 2007: 30).

Apropiándome de los postulados del crítico estadounidense, me interesa indagar entonces cuál es el prisma y el lenguaje desde el cual se articula la narrativa de la memoria propuesta en 1973. Pienso que responder estas interrogantes nos permitirá comprender también por qué esta obra conmemorativa no ha tenido grandes repercusiones en el campo cultural chileno, hecho que sin dudas ha influido en la falta de visibilidad y valoración del relato mnémico allí planteado.

\section{Desde el PRISma de Los Vencidos y los QUe Se Quedaron “AQuí”}

El título del poemario se refiere explícitamente a una fecha que no deja indiferente a ningún chileno, pero que su valoración -siempre en disputa- varía de persona en persona. A treinta años del golpe, ¿qué significado adquiere el año 1973 en la obra que nos convoca?

Mi lectura es que el ejercicio de hacer memoria se realiza desde el prisma de los vencidos, vale decir, de aquellos que vivieron el golpe de Estado y la posterior dictadura militar no solo como la interrupción abrupta de la Unidad Popular, sino como una catástrofe total:

Allí quedó la sangre de la República transformada en mierda.

Chile fue un estropajo desde ese preciso minuto. 
$[\ldots]$

Todo quedó destrozado ese 11 de

Septiembre de 1973

En mi propia alma (Cuevas 2003: 52-53)3.

Desde la óptica del sujeto textual, el golpe es sinónimo de una destrucción violenta. Palabras como "sangre", "mierda", "estropajo" y "destrozado" dan cuenta de ello. Ahora bien, la destrucción se vive tanto a nivel colectivo como individual. La herida perpetrada al Chile republicano es experimentada como propia por la voz, pues lo que ha sido aniquilado es un "Proyecto De Vida Común" (Cuevas 2003: 52), basado en el vínculo solidario entre trabajadores y estudiantes y a favor de los sectores populares del país. Ese día muere una forma particular de pensar y vivir la comunidad nacional, que según la poética de Cuevas fue destruida para siempre. De ahí la presencia constante del adjetivo "ex" en sus poemas para referirse a un país que fue y dejó de ser.

Magda Sepúlveda, en su artículo "El territorio y el testigo en la poesía chilena de la Transición", propone que los poetas de los 90 elaboran en sus textos la voz de un testigo imposible: "Quiero postular que el sujeto que habla en la mayoría de los textos de los poetas del noventa es el testigo imposible del cual habla Agamben en Lo que queda de Auschwitz" (Sepúlveda 2010: 4). Este tipo de testigo incorporado por la académica en su lectura corresponde a lo que Agamben también denomina los testigos "verdaderos" o "integrales", sujetos que experimentaron el horror nazi hasta el exterminio, dejando así una laguna narrativa asumida por los testigos sobrevivientes. Desde esta perspectiva, Sepúlveda analiza cómo en la poesía de Javier Bello, Germán Carrasco, Alejandra del Río y Andrés Anwandter, entre otros, las voces hablan sobre dicha imposibilidad testimonial, recurriendo a un lenguaje a ratos críptico, en el que predominan las referencias a territorios perdidos: "Nuevamente esta voz corresponde a un testigo imposible y no a un testigo real, porque el que efectivamente vivió esa circunstancia está muerto. [...] Este testigo habla sobre un hecho imposible de decir, de ahí lo figurativo de su lenguaje, característica que va a dominar la gran mayoría de los poemas de la Transición" (Sepúlveda 2010: 85).

En el caso de la poesía de Cuevas, predomina más bien una textualidad cercana al lenguaje coloquial, narrativo, la ironía y en diálogo con otros tipos de discursos extraliterarios; sin embargo, comparte con la generación de los náufragos la estrategia discursiva identificada y analizada por Sepúlveda: la creación de un hablante testigo. Sobre la base de dicha propuesta de lectura, podríamos señalar que Cuevas también elabora en 1973 la voz de un testigo, que inmerso en la sociedad chilena postdictatorial rememora sus vivencias de la Unidad Popular, el día del golpe y los diecisiete años de dictadura. Todo con el propósito de poner en escena la perspectiva de la derrota desde la cual se configura la narrativa de la memoria planteada en su obra. Ahora bien, creo es necesario precisar que en Cuevas el sujeto textual no es

\footnotetext{
Un recurso textual característico de la poesía postdictatorial de Cuevas es el uso de la barra oblicua o slash. Este signo gráfico es interpuesto en medio de los versos sin seguir un orden preestablecido, otorgando a la escritura del poeta una visualidad y sonoridad mutilada, que a mi juicio reproduce la fragmentación de la comunidad nacional puesta en escena en su obra. Debido a que el slash también se usa para marcar la separación entre los versos al momento de citar un poema, he decidido citar los textos de Cuevas en párrafos independientes, con el fin de evitar posibles confusiones.
} 
un testigo imposible, sino un testigo -en términos de Agamben- superstes y martis, es decir, un testigo sobreviviente y un testigo que tiene la vocación de recordar, respectivamente (Agamben 2000: 15-26). Por cierto, esta lectura está en deuda también con lo planteado por Galindo sobre la obra postdictatorial del poeta, quien ha destacado el carácter testimonial de su proyecto escritural: "La persistencia de la función testimonial, por medio de la cual el sujeto que habla muestra su compromiso con la materia de la que habla, sitúa al ex poeta en el espacio de la escritura como denuncia, aunque su afán no sea sólo éste" (Galindo 2002: 111).

En el marco del prisma de los vencidos, la poética de Cuevas introduce una particularidad: hablar sobre los que vivieron la dictadura en Chile. A lo largo de 1973, la voz reitera el deíctico de lugar "aquí", con el fin de reivindicar a quienes sufrieron la experiencia del régimen militar en el país y no en el exilio, conviviendo día a día con la represión, la clandestinidad, la tortura, la desaparición de los amigos ${ }^{4}$. En el poema "Biografía común", por ejemplo, la voz del testigo sobreviviente se refiere a sí mismo como "suscrito", término legal que define a aquel que suscribe con su firma un documento, lo que a mi parecer revela su afán por dejar un registro de cómo fue su vida cotidiana durante los años de dictadura. Desde esta perspectiva, describe con detalle las noches en que temía convertirse en un "caído" más, las "reuniones secretas" junto a otros sujetos clandestinos y las perversas técnicas usadas por los servicios de inteligencia para capturar a los disidentes, tal como se advierte en estos versos:

este suscrito se movía entre santa rosa/ matta/ la pintana/ Jamás el Centro.

el centro estaba vigilado/ día a día/ llevaban a los pobres detenidos/ en camionetas fiscales/ a reconocer a sus compañeros/ entre algún transeúnte (Cuevas 2003: 33).

El sujeto textual no puede sino recordar su historia de sobrevivencia y la de los que no sobrevivieron a la catástrofe para dar su testimonio. De hecho, en el mismo poema, hace alusión a quienes se refieren a él como "este tipo majadero" (Cuevas 2003: 34), dando cuenta de la sanción social que existe con respecto a los que no quieren dar vuelta la página, como han sugerido muchos políticos. Su vocación es rememorar la herida infringida sobre la comunidad nacional a partir del golpe, pero centrando su atención en aquellos sobre los que poco se dice en la narrativa de la memoria oficial: los que vivieron en la clandestinidad, los exonerados, los que participaron en las protestas de los 80 , los que se volvieron alcohólicos y, por cierto, los torturados y los desaparecidos. El propósito de la voz es poner en escena esa memoria herida y marginada, pues ha asumido - parafraseando a Todorov- el deber de acordarse y testimoniar (Todorov 2000: 218).

\footnotetext{
El afán por reivindicar a quienes vivieron la dictadura en Chile ha estado presente desde sus inicios en la poesía de Cuevas. Pienso, por ejemplo, en el poema "Aquí estuve" de Canciones rock para chilenos (1987), donde la voz ironiza en torno a la nostalgia de los exiliados, manifestada en un imaginario culinario de carácter rokhiano: "Aquí estuve estos casi trece años / no anduve al Sur de Francia / ni por Suecia / ni menos visite alguna de las Alemanias. / Por tanto no he echado de menos / cazuelas / arrollados / tortillas / vinos tintos" (Cuevas 1989: 70). También en el poema "De lo desgraciadamente sucedido entre un exiliado interior y un retornado" de Cánticos amorosos y patrióticos (1988), donde el sujeto de la enunciación pone en escena el encuentro entre los dos personajes mencionados en el título, que finalmente concluye en un desencuentro irreconciliable: "A, B se separan para no volver a verse / en el resto / de sus vidas" (Cuevas 1989: 79).
} 
Esta intención de rememorar se relaciona directamente con el título de la primera parte del libro "Exhumación". En términos etimológicos, esta palabra de origen latino nos remite en primer lugar a algo sepultado, que debe ser extraído desde las profundidades de la tierra para ser visible a todos (el prefijo "ex" significa 'fuera'o 'más allá' y "humus" 'tierra'). El diccionario de la Real Academia Española, por su parte, entrega tres acepciones del verbo "exhumar", que por cierto recuerdan la etimología de la palabra: 1) "desenterrar cadáveres o restos humanos"; 2) "desenterrar ruinas, estatuas, monedas, etc.”; 3 ) "sacar a la luz lo olvidado" (RAE 2001: en línea). A mi parecer, todos estos posibles significados permiten entender el ejercicio de memoria realizado en 1973 como un exhumar, en otras palabras, como un visibilizar o poner en escena las versiones del pasado que han sido silenciadas para resguardar el llamado consenso. Además, me parece importante destacar que la voluntad mnémica de la voz del testigo sobreviviente se realiza desde las ruinas, lo que a mi juicio se advierte en la apariencia desmembrada, fragmentada y mutilada del texto (reforzada por el uso de las barras oblicuas y también los títulos numerados de los poemas que no siguen un orden lógico), así como en la yuxtaposición algo caótica de los recuerdos. Acorde con esta idea, no puedo dejar de asociar la narrativa de la memoria elaborada en el poemario de Cuevas con "la metáfora arqueológica" (Lazzara 2007: 63) utilizada por Walter Benjamin para definir la memoria en su texto "Crónica de Berlín": "Quien aspire a acercarse al propio pasado sepultado ha de comportarse como el que exhuma un cadáver. Ello determina el tono, el talante de los verdaderos recuerdos. No hay que temer volver una y otra vez al mismo estado de cosas: diseminándolas como se disemina la tierra, revolviéndolas como se revuelve la tierra" (Benjamin 1995: 42). Si como plantea Richard los administradores del consenso optaron por elaborar un relato de la memoria casi indoloro, lo que Benjamin propone es no tener miedo a excavar, remover y dar paladas en las capas donde se aposenta el pasado. Pienso que el gesto realizado por la voz poética es este último. Desde su óptica, recordar significa ahondar allí donde la perspectiva oficial ha dicho que es mejor olvidar.

Un poema emblemático para ilustrar este afán por exhumar a los olvidados es "Poema 452 Se reitera por última vez". El título no deja de ser revelador, toda vez que indica que lo señalado en este discurso ha sido dicho repetidas veces, probablemente sin ser escuchado. Parafraseando un pasaje bíblico del Evangelio de Lucas ${ }^{5}$, la voz realiza un homenaje a los que participaron activamente en la Unidad Popular y luego se quedaron "aquí" durante la dictadura:

Paz en la Tierra a quienes se quedaron
aquí en la matanza diaria/ persecución/
prisión y tormento
despojados de cargos títulos y grados/
quema de cuerpos/ en la miseria más
grande que se tenga memoria/ Gloria a
los que fueron amarrados y rociados con

El intertexto bíblico recreado en el poema se circunscribe al episodio del nacimiento de Jesús y la visita de los pastores narrado en el Evangelio de Lucas. Específicamente, lo que la voz poética reelabora en su discurso es lo dicho por los ángeles en alabanza a Dios ante la venida del "salvador": "Y de pronto se juntó con el ángel una multitud del ejército celestial que alababa a Dios diciendo: "Gloria a Dios en las alturas y en la tierra paz a los hombres en quienes él se complace»" (Biblia de Jerusalén 1998: 1498). Este fragmento bíblico también es incorporado en las misas católicas cuando se reza el Gloria. 
bencina o acribillados sus brazos y ojos

a los militantes democráticos/ a la Coordinadora

Nacional Sindical/ y Comando

de Trabajadores Alamiro Guzmán/ Héctor

Cuevas/ Manuel Bustos/ Jano Jiménez. Y

la Asociación Gremial de Educadores de Chile

A desaparecidos y destrozados a lo largo

y ancho de la patria chilena

Paz/ Paz a sus almas (Cuevas 2003: 69-70).

Torturados, perseguidos, exonerados, desaparecidos, presos, sindicalistas, manifestantes, profesores y trabajadores. Personas anónimas y otras con nombre y apellido. Sobrevivientes y muertos. Todos los que lucharon contra el régimen de Pinochet caben en el homenaje realizado por la voz poética, que también emula los responsos en los que se pide por el descanso de los difuntos.

Desde esta perspectiva, me gustaría remitir a otro poema del libro, donde el sujeto textual -quien ficcionaliza su discurso bajo el nombre de "ismael cancino tapia"declara sin rodeos ni eufemismos su intención de hacer y legar un homenaje:

Quiero dejar aquí mi homenaje a todos quienes fueron parte /

de los más valientes ghettos de la resistencia 73-90 (Cuevas 2003: 27).

Si el homenaje implica un reconocimiento público en honor a alguien, en el caso de 1973 el propósito es homenajear, en tiempos de la Transición, a quienes no han sido considerados en la memoria oficial sobre la dictadura. En otras palabras, visibilizar a quienes fueron parte de la resistencia en contra del régimen militar y que una vez recuperada la democracia fueron olvidados mientras otros se llevaban los aplausos. De ahí la insistencia en señalar cómo sus cuerpos fueron heridos o el afán por nombrar a personas y asociaciones que realmente existieron, gesto que refuerza el carácter testimonial del texto. En este sentido, pienso que el poemario de Cuevas comparte con otros libros de poesía latinoamericana la intención de homenajear a las subjetividades ninguneadas por el discurso hegemónico, ya sea por su diferencia étnica, social, cultural o política. Pienso en Homenaje a los indios americanos (1970) de Ernesto Cardenal, donde la voz celebra los saberes, las lenguas y el modo de vida de las culturas indígenas ancestrales como la maya, azteca, inca y sioux, en oposición al sistema impuesto por la economía capitalista y las haciendas: "Un Imperio de ayllus/ ayllus de familias trabajadoras/ animales vegetales minerales/ también divididos en ayllus/ el universo entero todo un gran ayllu/ (y hoy en vez del ayllu: los latifundios)/ No se podía enajenar la tierra/ Llacta mama (la tierra) era de todos / Madre de todos" (Cardenal 1970: 59). También pienso en Bobby Sands desfallece en el muro (1983) de Carmen Berenguer, donde el relato acerca de la huelga de hambre del héroe irlandés funciona como un homenaje a las víctimas de la dictadura. Dice la autora en la contratapa del libro: "A través de Bobby Sands hago un homenaje a todos aquellos que luchan por liberar al hombre de la explotación, la miseria, el hambre y la tortura" (Berenguer 1983: s/n). En todos estos casos, homenajear se vuelve sinónimo de recordar, visibilizar y valorar.

Pero el poemario de Cuevas no solo constituye un gran homenaje a los vencidos y a los que permanecieron "aquí", sino también una reflexión crítica sobre el porqué 
de la derrota. La narrativa de la memoria planteada en 1973 implica decir las heridas de la dictadura, pero también cómo fue vivida la Unidad Popular y las razones de su fracaso. En este sentido, me parece fundamental la segunda parte del poemario, titulada "Testamentaria" y conformada por un solo poema. A mi juicio, el título es revelador, pues hace referencia al documento llamado testamento, donde las personas declaran su última voluntad y disponen de sus bienes para después de su muerte (RAE 2001: en línea). En la literatura, la reelaboración de este texto extraliterario es de larga data, por lo que a través del tiempo se pueden observar apropiaciones totalmente diversas. Tal como indica el crítico Marcial Rubio, "bajo la rúbrica de 'testamentos literarios' podemos encontrar textos en prosa y en verso; doctrinales o cómicos; de personas reales o ficticios; de personas o de animales; etc." (Rubio 2006: 242). Probablemente, uno de los testamentos literarios más conocidos sea el de don Quijote y en el caso chileno los poemas "Testamento (1)" y "Testamento (2)" del Canto General de Neruda ${ }^{6}$.

En el caso del poema de Cuevas, la voz poética no deja un legado material a otros, sino que sus recuerdos e interpretación personal sobre el devenir del gobierno de Allende. Para el testigo sobreviviente - despojado de sus sueños, generación y bienes a partir del golpe- sus memorias sobre dicha utopía revolucionaria constituyen un patrimonio, que debe ser atesorado por otros ${ }^{7}$. Desde esta perspectiva, la voz de "Testamentaria" recuerda con nostalgia las fábricas tomadas por los trabajadores, las calles llenas de multitudes gritando "El pueblo unido jamás será vencido", el trabajo realizado por las JAP en las poblaciones y las masas coreando "¡A parar la sedición!” (Cuevas 2003: 39-41). Inmerso en lo que para él es la desventura del Chile postdictatorial, rememora ese momento de su vida y la historia nacional como un periodo de enorme felicidad, que fue abruptamente cortado por el golpe de Estado:

Feliz fui en los años del Levantamiento popular unidad obrero estudiantil.

Hasta que devino en derrota total sangre/ dolor.

Y silencio por los siglos de los siglos.

Amén (Cuevas 2003: 41).

Si luego de la "derrota" todo fue silenciado (nótese cómo se reproduce este silencio en la fórmula religiosa incorporada en el cuarto verso por medio de la aliteración

\footnotetext{
En Canto General, Neruda construye una imagen de sí mismo como un poeta comprometido, lo que me permite entender sus poemas testamentarios a partir del género de la auto(r)ficción, definido como "aquellos relatos ficcionales en los que hay una 'intromisión' del autor in corpore o in verbis en el mundo narrado" (Toro et al. 2001: 21). Por ejemplo, en "Testamento (1)", el hablante expresa su voluntad de dejar a los sindicatos mineros su casa de Isla Negra, pues desea "que allí reposen los maltratados hijos/ de mi patria" (Neruda 2003: 624). De esta forma, ciertos datos biográficos son ficcionalizados al interior del discurso poético, problematizando creativamente las fronteras entre verdad y ficción, autobiografía y poesía.
}

\footnotetext{
Por cierto, esta lectura es coherente con otros libros de Cuevas, como Álbum del ex-Chile 1970-1973, donde el autor construye una narrativa sobre los tres años de gobierno de la Unidad Popular, imbricando poemas, anécdotas, titulares y fotografías de periódicos de la época. El objetivo de esta obra testimonial es explicada por Cuevas al inicio: "El gobierno de la UP es totalmente desconocido por los chilenos jóvenes. Durante 17 años de la proscripción dos o tres generaciones no supieron absolutamente nada, sino la tergiversación malévola. Nunca más se supo de Salvador Allende ni su verdad. Ni la epopeya de un pueblo. Aquí presento esta secuencia de hechos, fotografías, relatos, fragmentos, titulares de prensa popular que en el año 2006 fotografié en diversas bibliotecas. Remedos de una gran felicidad para mi generación. Y los pasos de la tragedia" (Cuevas 2008: s/n).
} 
del fonema /s/), lo que la voz hace es excavar ese pasado, poniendo en escena las acciones y las hablas de quienes protagonizaron el "levantamiento popular".

Pero el recuerdo no es idílico. El testigo también deja registro de lo que para él constituyen las causas de la derrota. Por un lado, el sabotaje mediático y económico por parte de la clase dirigente, que se negaba a aceptar lo que para ellos era un alzamiento de los rotos o los "upelientos". Como en los titulares de los periódicos oficialistas de la época, la voz señala: "Día a día se dispara difamación por las Cadenas Edwards y Cía." (Cuevas 2003: 39) o "La burguesía deja el país sin pan, transporte, carne ni azúcar" (Cuevas 2003: 40). Por otro lado, los dardos también apuntan a la misma izquierda, en especial a las cúpulas de los partidos políticos, que desde su punto de vista no fueron capaces de reconocer los errores cometidos y abandonaron a Allende:

\author{
Pero/ ya los partidos de obreros y empleados están siendo copados \\ se pierden en la conducción de los acontecimientos \\ en sus errores que después en medio del naufragio \\ no siempre van a reconocer hidalgamente: \\ Que fue un gran error no preparar la defensa \\ Que se quebró la unidad \\ Que dejaron solo al Presidente (Cuevas 2003: 41).
}

Contrario a la retórica militante, en la narrativa de la memoria elaborada en 1973 existe una mirada autocrítica en torno al actuar de los partidos de izquierda y sus dirigentes, a quienes la voz condena -siempre desde el humor-por su ortodoxia. En este contexto, destaca también el poema "Militante tonto", donde el sujeto de la enunciación ironiza en torno a las actitudes algo fanáticas de ciertos comunistas, que despreciaban a tipos como él y los chicos de su banda por emborracharse, ser rockeros y no apoyar la invasión checoslovaca (Cuevas 2003: 29). En definitiva, quien enuncia en el texto de Cuevas es un sujeto comprometido con la lucha de la Unidad Popular, pero que nunca encajó en el discurso disciplinado de los partidos políticos de izquierda ${ }^{8}$.

Luego de analizar algunos fragmentos de 1973, hemos advertido que la narrativa de la memoria propuesta en esta obra se elabora desde la óptica de los vencidos. Para ello se recurre a la voz de un testigo sobreviviente, que ha asumido el deber de recordar y hacer pública su propia versión del pasado. Su objetivo es dejar un registro de los caídos y los sobrevivientes invisibilizados por el libreto oficial, poniendo especial atención en quienes se quedaron "aquí". Por eso el sujeto textual señala a modo de ruego: "Y les pido: Nunca olviden la Gran gesta de esos derrotados" (Cuevas 2003: 28). Acorde con lo anterior, he entendido el ejercicio de memoria realizado en el poemario de Cuevas como una exhumación, donde distintos recuerdos del tiempo de la dictadura y la Unidad Popular se superponen de manera algo inconexa, poniendo en escena lo que ha sido borrado en la narrativa de la memoria pública. Los cordones industriales, las canciones de Quilapayún e Inti Illimani, el pedagógico, la UNCTAD, las reuniones clandestinas, los centros de tortura, quienes escondieron a un perseguido y las operaciones del Frente

\footnotetext{
$\mathrm{Al}$ respecto, se puede citar también el poema "El templo", donde la voz se refiere a la denostación por parte de los dirigentes y militantes del Partido Comunista hacia su persona: "A mí no me miran/ Yo he sido revisionista/ me junto con trotskistas y rockeros" (Cuevas 2003: 71). Por cierto, el espacio sagrado mencionado en el título constituye una referencia crítica hacia el partido político en cuestión.
} 
Patriótico Manuel Rodríguez, entre otras, son parte de las diversas escenas mnémicas que atraviesan la obra. Todo con el propósito de no dar vuelta la página y reivindicar la acción de quienes soñaron con una revolución socialista y luego formaron parte de la resistencia en contra del régimen de Pinochet. De ahí la posibilidad de entender este libro como un homenaje, pero también como un testamento.

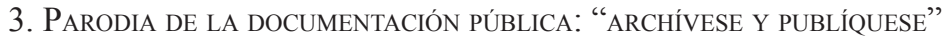

De acuerdo a Lazzara, al analizar la narrativa de la memoria de un texto no solo basta con identificar el prisma desde el cual se elabora. También es fundamental examinar cómo esa mirada sobre el pasado es traducida mediante un lenguaje específico. En el apartado anterior he mencionado algunos de los modelos textuales a los que el poemario de Cuevas echa mano para articular su poética del disenso, como por ejemplo el homenaje, el responso funerario o el testamento. Si bien estos y otros tipos de textos son resignificados poéticamente al interior de la obra, pienso que en 1973 predomina la siguiente estrategia representacional: la parodia de la documentación pública, con el fin de criticar la insuficiencia y homogeneización de la memoria oficial, que margina las versiones -para algunos incómodas- de quienes recuerdan y hablan por la herida.

Al inicio de la obra, el autor define su texto como "Esta documentación pública del realismo sucio chileno" (Cuevas 2003: s/n). A lo anterior se suma el título de uno de los poemas fundamentales del libro: "fragmentos/ mutilaciones y documentos públicos". A mi juicio, estos paratextos funcionan como señales para el lector del diálogo polémico que 1973 establece con los documentos elaborados por las instituciones públicas, siempre revestidos de un carácter oficial y solemne. Siguiendo la tradición iniciada por Nicanor Parra, y luego llevada al límite por Rodrigo Lira9, en distintos poemas del libro se recrea de forma paródica la documentación relativa a los procesos judiciales, como por ejemplo las declaraciones y las sentencias. De esta forma, la voz pone en escena su mirada crítica sobre el libreto oficial del consenso, cuestionando además qué tipo de documentos son erigidos como públicos, qué tan efectiva es la publicidad de éstos y los criterios para seleccionar aquellos que son conservados en los archivos del país.

A partir de Linda Hutcheon, entiendo la parodia como un fenómeno intertextual, que se define de la siguiente manera: "Elegí definir la parodia como una forma de repetición con distancia crítica e irónica, que marca la diferencia más que la similitud" (Hutcheon 2000: xii) ${ }^{10}$. Desde su perspectiva, la parodia implica la repetición

\footnotetext{
Sobre la "maquinaria paródica" de la poesía de Rodrigo Lira, el crítico Marcelo Rioseco señala: "Así vemos, tanto en Proyecto de obras completas como en Declaración jurada, la proliferación de textos cuyos formatos se reconocen rápidamente y que poco tienen que ver con los formatos convencionales de la poesía. De este modo, avisos económicos, (anti)manifiestos, declaraciones juradas (al estilo de las declaraciones notariales), bandos militares, cartas al director, "cartas abiertas" escritas para publicación de medios periodísticos, un currículum vitae, comunicados, edictos y poemas líricos se conjugan en un solo contenido. En este aspecto, Lira sigue muy de cerca los recursos de la escritura antipoética de Parra" (Rioseco 2013: 96). Pienso que la poesía de José Ángel Cuevas también es deudora de esta tradición paródica relativa a modelos textuales extraliterarios.

10 En el original: "I chose to define parody as a form of repetition with ironic critical distance, marking difference than similiraty" (Hutcheon 2000: xii).
} 
recontextualizada de un texto parodiado, donde la ironía crítica que marca la distancia entre ambos textos puede ser constructiva o destructiva. Su teoría se aparta así de las definiciones tradicionales de parodia, que la reducen a la idea de una imitación burlesca o ridícula (cf. Hutcheon 2000: 32). En este sentido, me parece importante también la distinción que la académica establece entre parodia y sátira: el "blanco" de la parodia es siempre una obra de arte o un discurso codificado, mientras que la sátira apunta hacia la corrección o ridiculización de asuntos humanos de carácter moral o social. Ahora bien, lo anterior no implica que la parodia sea una forma literaria neutral o que carezca de implicancias ideológicas o sociales. Muy por el contrario, aun cuando en algunos casos se actualiza con un fin conservador, puede llegar a ser transgresora, satírica, contestataria o subversiva: "La parodia no es, tampoco, una simple repetición diferencial o relacional de carácter post-estructuralista que enfatiza solo en la diferencia. La parodia, por cierto, puede ser disruptiva y desestabilizadora" (Hutcheon 2000: 101) ${ }^{11}$. En el caso de Cuevas, veremos que la parodia construida en 1973 remite principalmente a textos extraliterarios de carácter judicial y que su propósito es, ante todo, crítico.

Como ya fue señalado en el apartado anterior, la narrativa de la memoria elaborada en 1973 incluye una mirada autocrítica sobre el papel de los partidos de izquierda y sus dirigentes en el fracaso de la Unidad Popular. En este contexto, destaca "Poema $\mathrm{N}^{\circ}$ 1" (título que a mi parecer remite a los bandos militares), donde la voz reproduce la declaración del "simpatizante" Saravia y los dichos de los militantes que replican su posición. De esta forma, el texto se erige como una parodia de las declaraciones efectuadas por los testigos en un proceso judicial, donde el sujeto de la enunciación parece asumir la tarea del actuario, vale decir, el funcionario encargado de transcribir los testimonios de las personas citadas:

De conformidad a lo previsto

El simpatizante S. Saravia/ oriundo de la ciudad de Curicó/ viene en declarar que/ así como el proletariado alemán no cumplió su misión histórica en los años veinte; el programa/ de la UP/ en Chile/ tampoco fue viable.

Porque para tener éxito/ era preciso/ con antelación/ resolver el necesario respaldo militar $[\ldots]$.

Saravia afirma/ que lisa y llanamente la unión popular estaba fracasada de antemano/ como en verdad sucedió después.

Se le replica: Que los militares fueron una incógnita/ que nadie pensó jamás

la existencia de un Troglo/ un Moren/ / un Pinochet/ en sus filas/ Ni la formación de brigadas de exterminio contra su propio país

Grimaldi/ Cañas/ Venda Sexy/ nunca/ nunca/ jamás

Porque se confiaba ciegamente en las masas:/ Que ellas coparían los espacios.

Ellas cubrirían regimientos/ plazas/ avenidas/ y edificios públicos/ llegado el momento (Cuevas 2003: 11-12).

Expresiones como "De conformidad a lo previsto", "viene en declarar que", "Se le replica" y "afirma" constituyen una repetición con diferencia -al decir de Hutcheon-

11 En el original: "Nor, however, is parody simply a post-structuralist differential or relational kind of repetition that stresses only difference. Parody certainly can be disruptive and destabilizing" (Hutcheon 2000: 101). 
del lenguaje legal usado en las declaraciones judiciales. Lo interesante es que la parodia no solo se actualiza a nivel de lenguaje, sino también de contenido, pues el juicio que se pone en escena en el texto poético -cuyo título pide ser leído efectivamente como un poema- dice relación con el gobierno de Allende. Lo juzgado no es un asesinato o un robo, sino el desarrollo frustrado de un proyecto político revolucionario.

Desde esta perspectiva, el poema-declaración confronta dos miradas. Por un lado, la de los "simpatizantes" como el testigo Saravia, quien nunca creyó en la posibilidad real de llevar a cabo el programa de la Unidad Popular. Por otro lado, la de los militantes comunistas, quienes nunca imaginaron la existencia de los agentes de la DINA, la deslealtad del comandante en jefe nombrado por el mismo Allende o las casas de tortura. Estos últimos, según la declaración, siempre pensaron que las masas proletarias saldrían a las calles a defender el gobierno si el golpe venía. Sin embargo, Saravia piensa que la mirada de los militantes era algo ingenua, tal como se advierte en sus palabras citadas por la voz al final del poema:

Es una cosa de locos dice el simpatizante:

"Por eso fui un simpatizante nunca entré al partido", concluye. Archívese (Cuevas 2003: 12).

En relación con esta última cita, me interesa llamar la atención también sobre el mandato "archívese", que nos vuelve a remitir al modelo extraliterario de los documentos judiciales. Comúnmente, las sentencias o las resoluciones (en las que a veces se incluyen las declaraciones de testigos) finalizan con fórmulas algo arcaicas como "anótese", "comuníquese", "regístrese", "notifíquese" y "publíquese", que dan cuenta de la voluntad de hacer público el dictamen del juez. En el poema, la voz incorpora la fórmula "archívese" a modo de parodia, gesto que por cierto reviste una implicancia ideológica.

Si bien "archívese" puede ser entendido como la orden de poner fin a una causa, creo que en este caso la parodia se relaciona con la noción de archivo. De acuerdo a Ramón Alberch, el archivo es el lugar donde los documentos son preservados, custodiados y organizados: "un archivo está formado por los documentos que produce y recibe un individuo, una familia, una empresa o un organismo público en el ejercicio de sus actividades. [...] también se entiende por archivo el local o el edificio donde se organizan, conservan y consultan los documentos. Es un término que designa tanto el continente como el contenido" (Alberch y Cruz 2005: 10-11). A lo anterior agrego lo señalado por Wolfgang Bongers, quien explica que "los archivos son complejos sistemas culturales y epistemológicos que dependen de las técnicas de archivación, mientras que las memorias son elaboraciones de segundo grado, un trabajo específico (social, personal) con los materiales disponibles desde el archivo" (Bongers 2013: 247). Desde esta perspectiva, comprendo que los archivos cumplen una función fundamental en la elaboración de las memorias, pues proporcionan parte del material en que estas se sustentan. Por lo tanto, cuando la voz del testigo sobreviviente dice "archívese", polemiza con el criterio de selección del discurso oficial, que decide cuáles son los documentos incluidos/excluidos en los archivos del país.

Si la narrativa de la memoria elaborada bajo el imperativo del consenso ha borrado las versiones incómodas del pasado traumático, lo que hace la voz poética en "Poema $\mathrm{N}^{\circ} 1$ ” es justamente lo contrario. Simulando la situación de un proceso judicial, el 
sujeto de la enunciación deja registro de los recuerdos y las interpretaciones de quienes nunca han sido llamados a declarar, como por ejemplo el "simpatizante" Saravia. La poética de Cuevas reclama el derecho de las memorias heridas, marginadas y vencidas a ser consideradas como documentos públicos y legítimos, que también deben ingresar a los estantes de los archivos nacionales, donde se almacenan y conservan los escritos considerados como imprescindibles para entender el pasado. Así, por medio de la parodia de los documentos judiciales, 1973 instala una reflexión sobre los documentos y los archivos, que finalmente le permite poner en entredicho el libreto concertacionista sobre la dictadura militar y la Unidad Popular.

Quisiera recalcar que esta última estrategia textual -en la que me he detenido preferentemente- se repite a través del libro. Diversos poemas finalizan con fórmulas del tipo "Archívese y publíquese", como por ejemplo el texto "Oh, Fuerzas Armadas", donde la voz impugna a la institución mencionada por medio de distintas preguntas. Ahora bien, estos cuestionamientos sin respuestas por parte de los interrogados funcionan más bien como denuncias o acusaciones, que le permiten a la voz poética plantear su propia interpretación sobre los hechos. Desde su óptica, las Fuerzas Armadas y Carabineros de Chile defendieron los intereses de los capitales estadounidenses y la elite nacional, lo que finalmente concluyó en la tortura, desaparición y matanza de "su propio pueblo" y la destrucción de las empresas estatales (Cuevas 2003: 49-50). De ahí el tono lastimero del poema, marcado en la reiteración de la interjección "oh". En este sentido, el gran cuestionamiento del hablante es “¿Quién envenenó sus almas?” (Cuevas 2003: 50), es decir, qué condujo a estas instituciones a realizar tales aberraciones:

\author{
Oh, Fuerzas Armadas y Carabineros de Chile \\ ¿Por qué en la contienda pueblo/ oligarquía/ se pusieron al servicio de las facciones \\ del Gran Capital/ \\ aviones/ armas/ buques/ munición/ de todos los chilenos? (Cuevas 2003: 49)
}

Al final del poema, el sujeto textual entrega su propia conclusión: en el marco de la "sedición"12 derechista en contra del gobierno de Allende, las Fuerzas Armadas sellaron un pacto de mutuo apoyo y complicidad con la clase dirigente. Cito la última estrofa del texto, en la que se puede observar esta postura:

En esa sedición de los privilegiados/maniobras/ y campañas previas.

USTEDES SE DEJARON CONVENCER POR ELLOS.

Y ELLOS SE SIRVIERON ABSOLUTAMENTE DE USTEDES.

Archívese y publíquese (Cuevas 2003: 51).

\footnotetext{
Es interesante observar cómo el poema incorpora palabras que hoy tienen un carácter testimonial, como por ejemplo "sedición". Durante la UP, sus defensores se refirieron al boicot efectuado por la derecha y Estados Unidos mediante este término, que incluso fue incorporado en el ámbito musical por Quilapayún. Específicamente, me refiero a la canción "Vox populi" de Sergio Ortega, grabada por el grupo mencionado en 1971 y que forma parte del disco $L a$ Fragua. En la letra, "la voz del pueblo" se dirige a Allende para pedirle que ponga fin a la "conspiración" y "traición" de los "momios", caricaturizados burlescamente a partir de ideas asociadas al lujo y apellidos de origen vasco de difícil pronunciación, siempre vinculados en nuestro imaginario con la oligarquía: "La Paula Cocodrizábal / se ha comprado una mansión / y con los Hipopotegui / prepararan la traición. // Que empiece no más la fiesta / los momios no pasarán / les sacaremos la cresta / como dijo Corbalán. // ¡A parar la sedición!” (Quilapayún 1971: en línea).
} 
Por cierto, la voz desea dejar un registro de esta alianza perversa en su narrativa de la memoria, lo que incluso se evidencia en el cambio de tipografía: las mayúsculas resaltan ante la mirada del lector una versión de los hechos que se desea visibilizar a toda costa. En este sentido, la reproducción paródica de la fórmula "Archívese y publíquese" también indica una polémica hacia el relato de la memoria oficial, donde este tipo de interpretaciones sobre el pasado han sido silenciadas. Como la declaración del testigo Saravia o la historia de Titho Tello (un antiguo militante comunista, que se volvió alcohólico luego de la derrota y hoy ya nadie recuerda ${ }^{13}$ ), esta mirada crítica sobre el actuar de las Fuerzas Armadas y Carabineros de Chile ha sido borrada. Hablar por la herida, como lo hace este testigo sobreviviente, parece inconveniente en tiempos donde se privilegian los acuerdos.

Otro poema emblemático de 1973, que permite advertir la parodia de la documentación pública, es "fragmentos/ mutilaciones y documentos públicos". Tal como el título lo anuncia, el testigo sobreviviente pone en escena distintos "fragmentos" de lo que, según su perspectiva, debiesen ser considerados "documentos públicos" sobre el periodo de la dictadura militar y el gobierno de Allende. Como en otros textos del libro, la disposición visual del poema se presenta como un cuerpo mutilado. No solo por las barras oblicuas que fisuran los versos, sino también por los cortes establecidos entre las estrofas, cada una de las cuales es antecedida por subtítulos numéricos en desorden (como 1.5., 1.3, 1.1, 1.6, etc.), que recuerdan las múltiples divisiones numeradas de los textos legales y judiciales. Desde esta perspectiva, pienso que la parodia propuesta en el texto reproduce a nivel de significante el desmembramiento de la comunidad nacional, que aún no logra reencontrarse en la elaboración de una memoria realmente colectiva y compartida.

Lo interesante de este poema es que pone en evidencia -más que cualquier otro texto del libro- el discurso marcadamente dialógico del testigo sobreviviente. El objetivo de la voz poética es visibilizar las hablas, los recuerdos, las versiones y las acciones de distintos actores sociales caídos en el olvido o un silencio cómplice, para lo cual incorpora en su propio discurso algunos fragmentos de lo que Bajtin denominó un "enunciado ajeno" o una "voz extraña" (Bajtin 2012: 340). Por ejemplo, la voz recrea los dichos de algunos agentes de la CNI y DINA sometidos a juicios durante la Transición (cfr. Cuevas 2003: 13) y también las hablas de sujetos que representan distintas perspectivas al interior de la izquierda: clandestinos, exiliados, dirigentes, militantes y simpatizantes (cfr. Cuevas 2003: 15-18). Asimismo, el sujeto textual representa algunos acontecimientos olvidados por la lógica de la amnesia colectiva, que a su juicio deben ser recordados. Así, en la estrofa subtitulada “3.1”, menciona los nombres de algunos políticos, economistas, jueces, empresarios, abogados, militares $\mathrm{y}$ agentes de los servicios de inteligencia involucrados activamente en la dictadura y que hoy ocupan renombrados cargos en sus respectivas áreas de trabajo:

3.1.

Nunca olviden a los señores: A. Edwards/ Jarpa/ Frei/ Juan de Dios Carmona/ Nixon/ Kissinger/ Contreras Sepúlveda/ Laureani/ Cevallos/ / Guzmán Errázuriz/ Bardón/ Pablo Rodríguez/ Baharona, Brady/ Benavides/ Fernández, Madariaga/ El Troglo/ Mar-

13 La historia de este personaje es relatada por la voz del testigo sobreviviente en el texto "Poema 212", que finaliza de la siguiente manera: "Nadie lo toma en cuenta / ni le hace caso / le dicen Borrachoff / en el barrio cuando pasa. // Archívese, comuníquese y publíquese" (Cuevas 2003: 57). 
chenko/ José Piñera/ De Castro/ Ponce Lerou/ El fiscal Torres/ Pérez de Arce/ Silvia Pinto/ Fuentes Morrison/ Otero Echeverría/ Chico Durán/ González Alfaro, Bombal/ Iturriaga Neumann/ Cuadra, Büchi/ y por supuesto Pinochet entre tantos/ tantos otros (Cuevas 2003: 17).

Desde el prisma de los vencidos expuesto en el poema, la responsabilidad de las heridas perpetradas durante la dictadura recae no solo en los militares, sino también en los civiles. A lo anterior se añade la intención de visibilizar la responsabilidad de Estados Unidos en el golpe, incorporando en esta lista al presidente Richard Nixon y su consejero de seguridad nacional Henry Kissinger. Desde esta perspectiva, creo que la estrategia textual desarrollada en este fragmento puede ser asociada con la acción política conocida en Chile como "funa", término que Mabel García utiliza en sus estudios sobre poesía mapuche para referirse a uno de los recursos puestos en práctica por esta poética, consistente en "particularizar y poner en evidencia a sujetos históricamente reconocibles" (García 2006: 188). Lo que hace la poética de Cuevas es el mismo gesto de desenmascaramiento, pero en relación con los actores de la dictadura militar.

Al examinar cómo se traduce verbalmente la catástrofe dictatorial en 1973, hemos advertido que el ejercicio mnémico realizado por el testigo sobreviviente consiste en exhumar los retazos de hablas, recuerdos y acontecimientos olvidados en aras del consenso. Mediante la parodia de la documentación pública, en especial la judicial, el texto pone en escena la óptica de quiénes hablan y recuerdan desde la herida, legitimando su derecho a formar parte de los documentos y archivos nacionales, a partir de los cuales se elaboran los relatos sobre el pasado. Desde esta perspectiva, la voz señala en uno de los poemas: "Ahora todo está lleno de heridas/ cicatrices/ costras/ sangre seca/ entre el papeleo" (Cuevas 2003: 34). Su objetivo es visibilizar todos esos rastros de cuerpos golpeados, heridos y mutilados inscritos entre múltiples papeles, que de no volverse públicos caerán en el olvido. Además, es importante señalar que la referencia a los textos judiciales no es un gesto casual ni menos neutral, pues éstos remiten a un discurso del poder, cuyo lenguaje especializado, técnico y a ratos oscuro da cuenta de un saber excluyente, del cual el sujeto de la enunciación ha decidido apropiarse críticamente. La parodia, entonces, deviene en un recurso subversivo, que no solo problematiza la retórica del Poder Judicial, sino también la manera en que ejerce su función social, a saber, impartir justicia.

\section{Hacia la (RE)ESCRitura De la MEMORia COlectiva}

De acuerdo a Walescka Pino-Ojeda, la retórica de la reconciliación promovida durante la Transición devino en una exigencia de perdón sin justicia y una privatización del dolor de las víctimas y sus familiares, produciéndose una falta de conciliación entre la memoria oficial y la memoria privada de quienes hablan y recuerdan desde una herida todavía abierta:

La fórmula reconciliatoria ha sido enunciada como concerniente a la sociedad amplia, no obstante, los procedimientos discursivos que han nombrado el dolor, lo han privatizado, pues en definitiva son quienes sufren y recuerdan los que deben perdonar, y luchan por hacer coincidir "sus" memorias privadas con las sociales, pero también 
lidian para que el acto humanista de indultar no sea a expensas del olvido ético-jurídico social e histórico (Pino-Ojeda 2011: 146).

Si bien la Concertación reconoció los crímenes de la dictadura en documentos como el Informe Rettig y el Informe Valech, finalmente nunca se produjo una visibilización efectiva de estos compendios de la memoria y menos aún una promoción de la justicia.

Desde esta perspectiva, 1973 de Cuevas se erige como una poética del disenso y paródica, que asumiendo la óptica de los vencidos busca poner en escena la memoria herida y marginada del libreto consensuado durante la Transición. Sin lugar a dudas, es fundamental que en la sociedad chilena existan distintas narrativas de la memoria sobre el período dictatorial, que den cuenta de los diversos puntos de vista y experiencias; no obstante, también es importante compartir un relato representativo, que nos permita vivir juntos e impida la negación o cuestionamiento de los crímenes ocurridos $^{14}$. Lo preocupante, a mi juicio, es que las memorias del disenso no gozan de la visibilidad y valoración necesaria para influir realmente en la (re)escritura de la memoria colectiva de la nación. Por eso, quizás, la voz del testigo sobreviviente dice con tanta insistencia "Archívese y publíquese", esperando que algún día su versión herida del pasado sea un documento. Un documento público.

\section{OBRAS CITADAS}

Agamben, Giorgio. 2000. Lo que queda de Auschwitz. El archivo y el testigo. Homo sacer III. Trad. Antonio Gimeno Cuspinera. Valencia: Pre-Textos.

Alberch Fugueras, Ramón y José Ramón Cruz Mundet. 2005. ¡Archívese! Los documentos del poder. El poder de los documentos. Madrid: Alianza.

Bajtin, Mijail. 2012. Problemas de la Poética de Dostoievski. Trad. Tatiana Bubnova. México: Fondo de Cultura Económica.

Benjamin, Walter. 1995. “Crónica de Berlín”. Personajes alemanes. Trad. Luis Martínez de Velasco. Barcelona: Paidós.

Berenguer, Carmen. 1983. Bobby Sans desfallece en el muro. Santiago: La Autora.

Biblia de Jerusalén. 1998. Bilbao: Desclée De Brouwer.

Bongers, Wolfgang. 2013. "Archivo, memoria y subversión: el cine chileno de postdictadura, con apuntes de análisis sobre Archipiélago (1992) y Amnesia (1994)”. Chasqui Revista de Literatura Latinoamericana Special Issue 5: 245-255.

Barahona de Brito, Alexandra, Paloma Aguilar Fernández y Carmen González Enríquez. 2002. "Introducción". Las políticas hacia el pasado. Juicios, depuraciones, perdón y olvido en las nuevas democracias. Eds. Baharona de Brito, Alexandra, Paloma Aguilar Fernández y Carmen González Enríquez. Trad. Jesús Cuellas Menezo y María Cóndor Orduña. Madrid: Ediciones Istmo.

Cardenal, Ernesto. 1970. Homenaje a los indios americanos. Santiago: Universitaria.

Cuevas, José Ángel. 1989. Adiós Muchedumbres. Santiago: Editorial América del Sur. . 2003. 1973. Santiago: LOM. 2008. Álbum del ex-Chile 1970-1973. Santiago: Calabaza del Diablo.

${ }_{14}$ Tal como señala Daniel Link, "el ámbito político de las prácticas de la memoria sigue siendo nacional, no posnacional o global. Lo que se juega en cada una de esas políticas es la singularidad de lo viviente, el modo de vivir juntos y el lugar en que ese vivir juntos ocupa no una memoria unánime sino una memoria compartida, pública" (Link 2013: 22). 
2009. Canciones oficiales. Santiago: Ediciones UDP.

2012. Maquinaria Chile y otras escenas de poesía política. Santiago: LOM.

Galindo, Óscar. 2002. "Autoritarismo, enajenación y locura en la poesía chilena de fines del siglo XX. Zurita, Maquieira, Cuevas". América Latina Hoy 30: 97-118.

García Barrera, Mabel. 2006. "El discurso poético mapuche y su vinculación con los "temas de resistencia cultural". Revista chilena de literatura 68: 169-197.

Hutcheon, Linda. 2000. A Theory of Parody. The Teachings of Twentieth-Century Art Forms. Urbana and Chicago: University of Illinois Press.

Huyssen, Andreas. 2007. "Pretéritos presentes: medios, política, amnesia". En busca del futuro perdido. Cultura y memoria en tiempos de globalización. Trad. Silvia Fehrmann. Buenos Aires: Fondo de Cultura Económica.

Lagos, Ricardo. 2003. No hay mañana sin ayer. Recuperado de http://bibliotecadigital.indh. $\mathrm{cl} /$ handle/123456789/183

Lazzara, Michael. 2007. Primas de la memoria: narración y trauma en la transición chilena. Santiago: Cuarto Propio.

Link, Daniel. 2013. "Cine y Dictadura: la problemática del archivo y la memoria expandida". Chasqui Revista de Literatura Latinoamericana Special Issue 5: 19-31.

Moulián, Tomás. 2002. Chile actual. Anatomía de un mito. Santiago: LOM.

Neruda, Pablo. 2003. Canto General. Madrid: Cátedra.

Pino-Ojeda, Walescka. 2011. Noche y niebla: neoliberalismo, memoria y trauma en el Chile postautoritario. Santiago: Cuarto Propio.

Quilapayún. 1971. "Vox Populi”. Recuperado de http://www.quilapayun.com/canciones/voxpopuli.php

Real Academia Española de la Lengua. 2001. Diccionario de la lengua española. Recuperado de http://www.rae.es/

Richard, Nelly. 2001a. Residuos y metáforas (Ensayos de crítica cultural sobre el Chile de la Transición). Santiago: Cuarto Propio.

. 2001b. "Recordar el olvido". Volver a la memoria. Raquel Olea y Olga Grau (compiladoras). Santiago: LOM-La Morada.

2004. "Presentación”. Utopía(s) 1973-2003. Revisar el pasado, criticar el presente, imaginar el futuro. Ed. Nelly Richard. Santiago: Universidad Arcis.

Rioseco, Marcelo. 2013. "La maquinaria paródica de Rodrigo Lira". Maquinarias deconstructivas. Poesía y juego en Juan Luis Martínez, Diego Maquieira y Rodrigo Lira. Santiago: Cuarto Propio.

Rubio, Marcial. 2006. “Testamentos poéticos burlescos. Hacia la definición de un subgénero literario popular”. La literatura popular impresa en España y la América colonial. Formas y temas, géneros, funciones, difusión, historia y teoría. Eds. Pedro Manuel García Cátedra et al. Salamanca: Seminario de Estudios Medievales y Renacentistas.

Sepúlveda, Magda. 2008. "Metáforas de la higiene y la iluminación en la ciudad poetizada bajo el Chile autoritario". Acta Literaria 37: 67-80.

. 2010. "El territorio y el testigo en la poesía chilena de la Transición". Estudios Filológicos 45: 79-92.

Todorov, Tzvetan. 2000. Los abusos de la memoria. Barcelona: Paidós.

Toro, Vera, Sabine Schlickers y Ana Luengo. 2010. "La auto(r)ficción: modelizaciones, prob-lemas, estado de la investigación”. La obsesión del yo. La auto(r) icción en la literatura española y latinoamericana. Eds. Toro Vera, Sabine Schlickers y Ana Luengo. Vervuert: Ediciones Iberoamericana. 